\title{
Assessment of mineral intake in the diets of Polish postmenopausal women in relation to their BMI-the RAC-OST-POL study
}

\section{Mineral intake in relation to BMI}

\author{
Dominika Głąbska ${ }^{\text {(BD }}$, Dariusz Włodarek', Aleksandra Kołota', Aleksandra Czekajło², Bogna Drozdzowska ${ }^{3}$
} and Wojciech Pluskiewicz ${ }^{4}$

\begin{abstract}
Background: The diets of postmenopausal women in Western countries tend to be deficient in minerals, even if the energy value is at the recommended level. The objective of the presented population-based cohort study was to assess the intake of minerals (sodium, potassium, calcium, phosphorus, magnesium, iron, zinc and copper) in the diets of women aged above 55 years and to analyse the relations between BMI and mineral intake in this group.

Methods: The study was conducted in a group of 406 women who were randomly recruited from the general population of those aged above 55 years. The main outcome measures included BMI, reported sodium, potassium, calcium, phosphorus, magnesium, iron, zinc and copper intake assessed by dietary record (conducted during two typical, non-consecutive days). The distribution was verified with the use of the Shapiro-Wilk test. The comparison between groups was conducted using ANOVA with the LSD post hoc test or Kruskal-Wallis ANOVA with multiple comparisons. A comparison of satisfying nutritional needs was conducted using the chi-square test.

Results: Normal body weight individuals were characterised by lower sodium intake per $1000 \mathrm{kcal}$ of diet than obese class II and III individuals (BMI $\geq 35.0 \mathrm{~kg} / \mathrm{m}^{2}$ ). Overweight individuals were characterised by lower potassium and magnesium intake per $1000 \mathrm{kcal}$ of diet than obese class I individuals (BMl $\epsilon<30.0 ; 35.0 \mathrm{~kg} / \mathrm{m}^{2}$ ). The majority of individuals was characterised by insufficient potassium, calcium and magnesium intake. No differences in satisfying nutritional needs between BMl groups were observed for all minerals.

Conclusions: Following an improperly balanced diet was observed in the group of postmenopausal female individuals analysed. It was stated that the daily intake of all the assessed minerals was not BMI-dependent for the postmenopausal female individuals, but the nutrient density of diet (for sodium, potassium and magnesium) was associated with BMI.
\end{abstract}

Keywords: BMI, Intake, Minerals, Postmenopausal women

\footnotetext{
* Correspondence: dominika_glabska@sggw.pl

${ }^{1}$ Department of Dietetics, Faculty of Human Nutrition and Consumer

Sciences, Warsaw University of Life Sciences-SGGW, 159c Nowoursynowska

Street, 02-776 Warsaw, Poland

Full list of author information is available at the end of the article
} 
Table 1 Patients' characteristics, accompanied by comparison between BMl groups, RAC-OST-POL study, May 2010

\begin{tabular}{|c|c|c|c|c|c|}
\hline Group & Calculated value & Age (years) & Weight (kg) & Height (cm) & BMI $\left(\mathrm{kg} / \mathrm{m}^{2}\right)$ \\
\hline \multirow[t]{5}{*}{ Total $N=405$} & Mean & 66.5 & 74.3 & 155.9 & 30.6 \\
\hline & SD & 7.9 & 13.6 & 5.8 & 5.4 \\
\hline & Median & $65.3^{+}$ & $73.0^{\dagger}$ & 156.0 & $30.0^{\dagger}$ \\
\hline & Minimum & 55.0 & 44.0 & 136.0 & 19.7 \\
\hline & Maximum & 92.2 & 120.0 & 171.0 & 47.4 \\
\hline \multirow[t]{5}{*}{ BMl $\epsilon<18.5 ; 25.0 \mathrm{~kg} / \mathrm{m}^{2}, N=61$} & Mean & 63.5 & 57.1 & 157.0 & 23.1 \\
\hline & SD & 6.7 & 5.6 & 6.5 & 1.5 \\
\hline & Median & $61.8^{\text {ta }}$ & $58.0^{\mathrm{a}}$ & 157.0 & $23.5^{t a}$ \\
\hline & Minimum & 55.2 & 44.0 & 141.0 & 19.7 \\
\hline & Maximum & 79.5 & 68.0 & 171.0 & 25.0 \\
\hline \multirow[t]{5}{*}{ BMl $\epsilon<25.0 ; 30.0 \mathrm{~kg} / \mathrm{m}^{2}, N=140$} & Mean & 66.3 & 67.4 & 156.4 & 27.5 \\
\hline & SD & 8.2 & 5.9 & 5.4 & 1.4 \\
\hline & Median & $64.5^{\mathrm{tab}}$ & $67.0^{\mathrm{b}}$ & 156.0 & $27.3^{t b}$ \\
\hline & Minimum & 55.0 & 52.0 & 141.0 & 25.1 \\
\hline & Maximum & 92.2 & 83.0 & 170.0 & 30.0 \\
\hline \multirow[t]{5}{*}{ BMl $\epsilon<30.0 ; 35.0 \mathrm{~kg} / \mathrm{m}^{2}, N=118$} & Mean & 67.3 & 78.5 & 155.5 & 32.4 \\
\hline & SD & 7.8 & 7.0 & 6.1 & 1.4 \\
\hline & Median & $67.8^{t b}$ & $78.0^{c}$ & 156.0 & $32.4^{t c}$ \\
\hline & Minimum & 55.1 & 63.0 & 136.0 & 30.0 \\
\hline & Maximum & 84.1 & 95.0 & 171.0 & 34.9 \\
\hline \multirow[t]{5}{*}{$\mathrm{BMI} \geq 35.0 \mathrm{~kg} / \mathrm{m}^{2}, N=86$} & Mean & 67.7 & 92.2 & 155.0 & 38.4 \\
\hline & SD & 7.7 & 9.9 & 5.3 & 2.9 \\
\hline & Median & $67.3^{t b}$ & $92.0^{\mathrm{d}}$ & 155.0 & $37.6^{t d}$ \\
\hline & Minimum & 55.1 & 71.0 & 139.0 & 35.0 \\
\hline & Maximum & 89.0 & 120.0 & 166.0 & 47.4 \\
\hline$p^{\mathrm{e}}$ & $p^{\mathrm{e}}$ & 0.0057 & 0.0000 & 0.1299 & 0.0000 \\
\hline
\end{tabular}

${ }^{\dagger}$ Variable was not normally distributed (verified by the Shapiro-Wilk test; $p<0.05$ )

$\mathrm{a}, \mathrm{b}, \mathrm{c}, \mathrm{d}$ Mean/median values within the column with unlike superscript letters were significantly different $(p<0.05)$

e Differences assessed by the ANOVA/Kruskal-Wallis ANOVA

\section{Background}

The diets of postmenopausal women in Western countries generally tend to be improperly balanced. Female subjects are characterised by a too low intake of vitamins, especially of vitamins D and E [1], as well as of B vitamins [2]. Their diets are also deficient in minerals, especially in calcium [3], magnesium [4], iron [5], zinc [6] and iodine [7]. The above-mentioned low intake of specific nutrients is often observed even if the energy value of the diet is proper $[8,9]$.

Simultaneously, the results of the analysis encompassing Polish postmenopausal women indicate insufficient energy intake [10] and energy intake decreasing over the years [11], even for overweight and obese individuals [12]. The results from other Western countries are similar [13-15]. However, the low energy intake, obtained from the dietary record or food frequency questionnaire, may be associated with the limitations of the above-mentioned methods [16].
This may result from the fact that individuals tend to underestimate the quantity of consumed food products, which is observed especially in patients with an increased amount of body fat [17], with chronic diseases [18], a lower education level [19], those dissatisfied with their body image [20] and motivated to follow a proper diet [21].

As a consequence, the conclusions associated with nutrient intake, especially the macronutrients and energy value of the diet, must be prudential and balanced [22]. This is even reflected in the Polish recommendations to assess the energy value of the diet, where it is specified that the energy value of the diet in groups of individuals should not be assessed on the basis of values calculated from the dietary record or food frequency questionnaire but rather on the basis of BMI [23]. If individuals have a recommended BMI, their intake is constant and the body mass does not change, it may be interpreted that the energy intake is at the recommended level. 


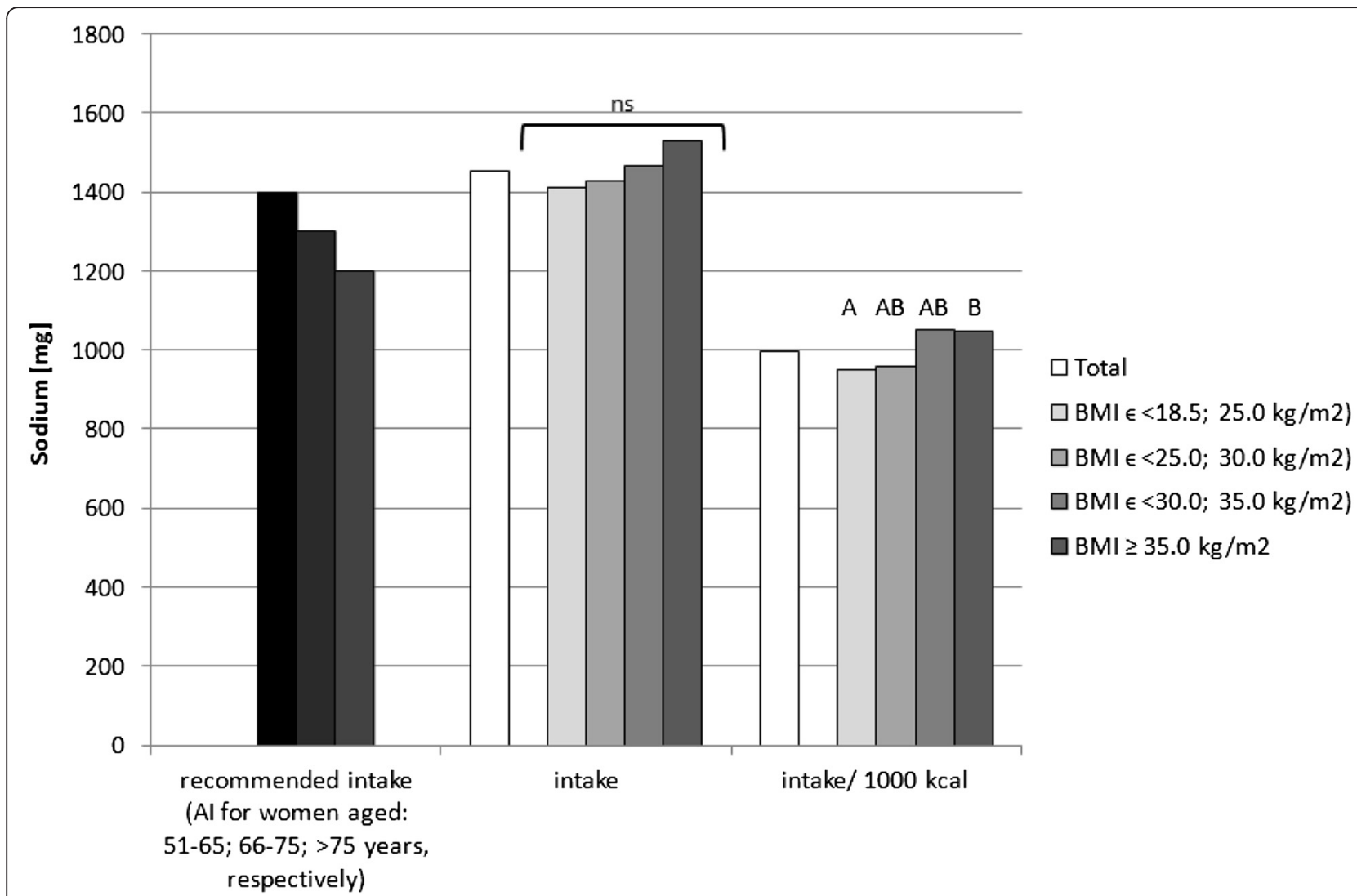

Fig. 1 Recommended sodium intake [34], accompanied by comparison of sodium intake ( $p=0.8574)$ and of sodium intake per $1000 \mathrm{kcal}$ of diet $(p=0.0081$ ) between BMl groups, in analysed healthy women aged $>55$, RAC-OST-POL study, May 2010. Al Adequate Intake level, ns not significant differences. $A$ and $B$ values with unlike letters were significantly different $(p<0.05)$

The aim of the study was to assess the intake of minerals (sodium, potassium, calcium, phosphorus, magnesium, iron, zinc and copper) in the diets of Polish women aged above 55 years in comparison with the recommendations and to analyse relations between BMI and mineral intake in this group (RAC-OST-POL study data).

\section{Methods}

The RAC-OST-POL study was conducted in a random group of Polish women aged above 55 years who were recruited from the general population of women aged above 55 years in the District of Raciborz, in the south of Poland. The age group above 55 years old was randomly chosen on the basis of guidelines on standard international age classifications by the United Nations Organization based on World Health Organization classification [24]. Of all the women inhabiting the region who were above 55 years old at the time of enrolment, $10 \%$ were randomly chosen on the basis of their personal identity numbers (1750 individuals) and invited to participate in the study, which was conducted in May 2010. This study was conducted according to the guidelines laid down in the Declaration of Helsinki, and all procedures involving human subjects were approved by the Ethics Committee of the Medical University of Silesia, Katowice, Poland. A written informed consent was obtained from all participants.

A group of 979 individuals responded positively to the invitation, and of these, a total of 405 individuals completed a 2-day dietary record during the whole following month (no dietary records were rejected during the analysis). Body weight and height were measured with a standard medical balance and used to calculate the BMI $\left(\mathrm{kg} / \mathrm{m}^{2}\right)$. On the basis of the conducted interview, the physical activity level in the assessed group was stated to be low-to-moderate and stable body mass condition was declared by the vast majority of individuals for the previous 3 months.

The assessment of diet was based on self-reported data from the patients' 2-day dietary record conducted on random days. Such record was also applied in the Nationwide Food Consumption Survey [25]. Two random days were chosen, as the analysed women in general were not working professionally, and in the research of other authors [26], no differences between weekdays and days of the weekend were proved in female 


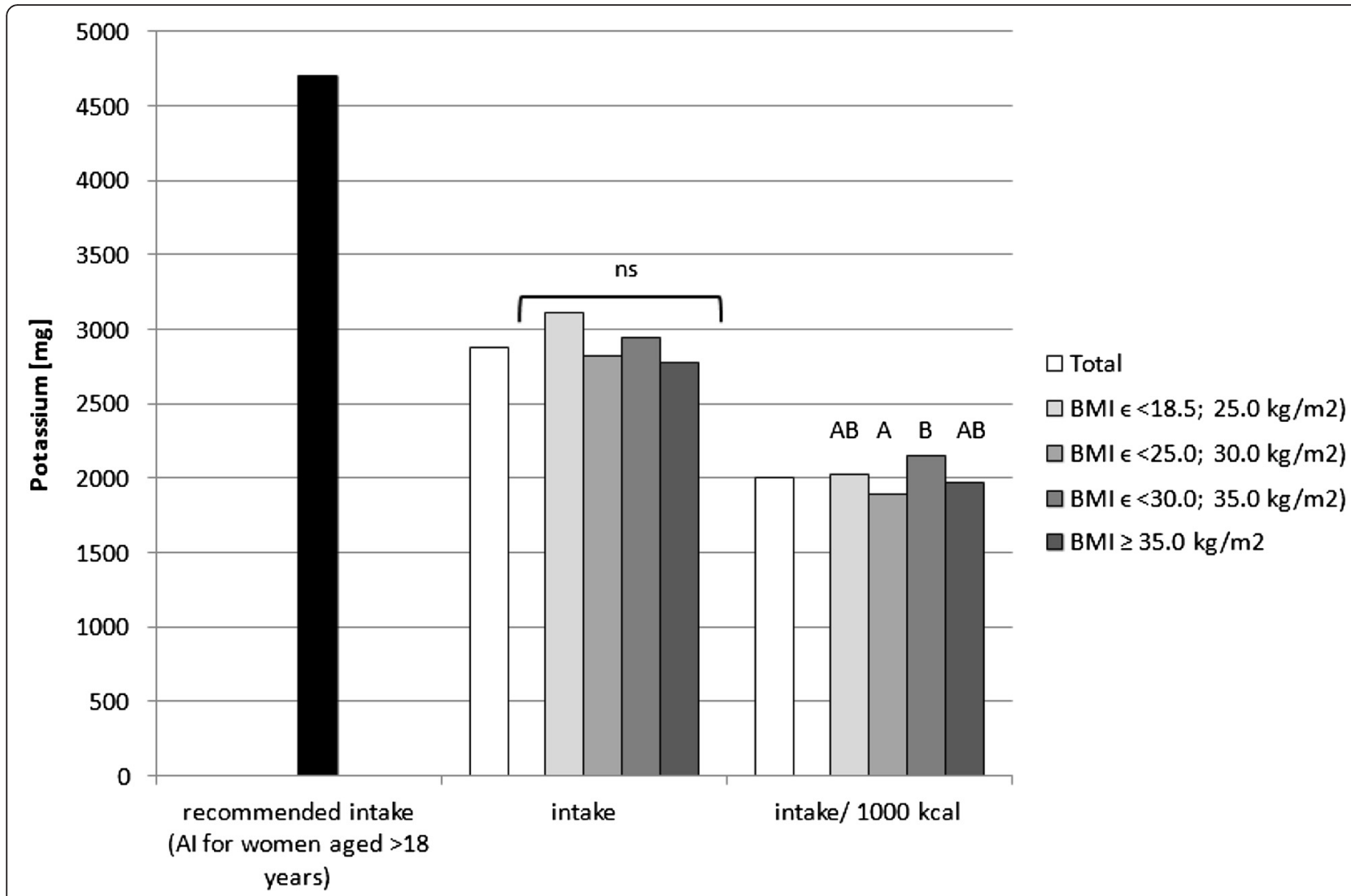

Fig. 2 Recommended potassium intake [34], accompanied by comparison of potassium intake ( $p=0.0726)$ and of potassium intake per $1000 \mathrm{kcal}$ of diet $(p=0.0169$ ) between BMI groups, in analysed healthy women aged $>55$, RAC-OST-POL study, May 2010. Al Adequate Intake level, ns not significant differences. $A$ and $B$ values with unlike letters were significantly different $(p<0.05)$

individuals who were not working professionally, as their diet on weekdays and days of the weekend did not differ. Participants were asked to conduct a dietary record during two typical, non-consecutive days. To provide reliable estimates of food intake, the participants were instructed about the principles of conducting a dietary record and about the necessity of accurate and scrupulous recording of all food products consumed and beverages drunk. If they were not able to conduct a weighted food record, they were asked to conduct an estimated food record (using estimated serving sizes).

The results were analysed by using Polish dietician software, "Dietetyk 2," and the Polish database of the nutritional values of products [27], with additional label information collected by the participants, while sodium chloride addition during the preparation of meals was not taken into account. The obtained average nutritional value of the analysed diets (mean of two analysed days) was the basis for further analysis.

The mineral contents in the diets were compared with the recommendations for healthy women (Table 1); for calcium, phosphorus, magnesium, iron, zinc and copper at the Estimated Average Requirement (EAR) level; and for sodium and potassium at the Adequate Intake (AI) level because the EAR level had not been established [28]. In a previously conducted assessment of the diet of women being analysed, it was concluded that a number of women were unable to satisfy their calcium requirement exclusively from their diet [29].

Statistical analysis was conducted using Statistica software version 8.0 (StatSoft Inc.) and Statgraphics Plus for Windows 4.0. The distribution of the analysed factors was verified by using the Shapiro-Wilk test. The comparison of mineral intake between groups was conducted using ANOVA accompanied by the LSD post hoc test as well as, in the case of distribution that was different than normal, using Kruskal-Wallis ANOVA accompanied by multiple comparisons. The median values are presented in the figures. A comparison of satisfying nutritional needs was conducted using the chi-square test. An additional statistical analysis (chi-square test) was performed in order to confirm that the analysed population could be treated as a representative subsample-it was verified whether the mean age in the analysed subpopulation matched the mean age in the general population. The two-sided level of significance $p \leq 0.05$ was accepted. 


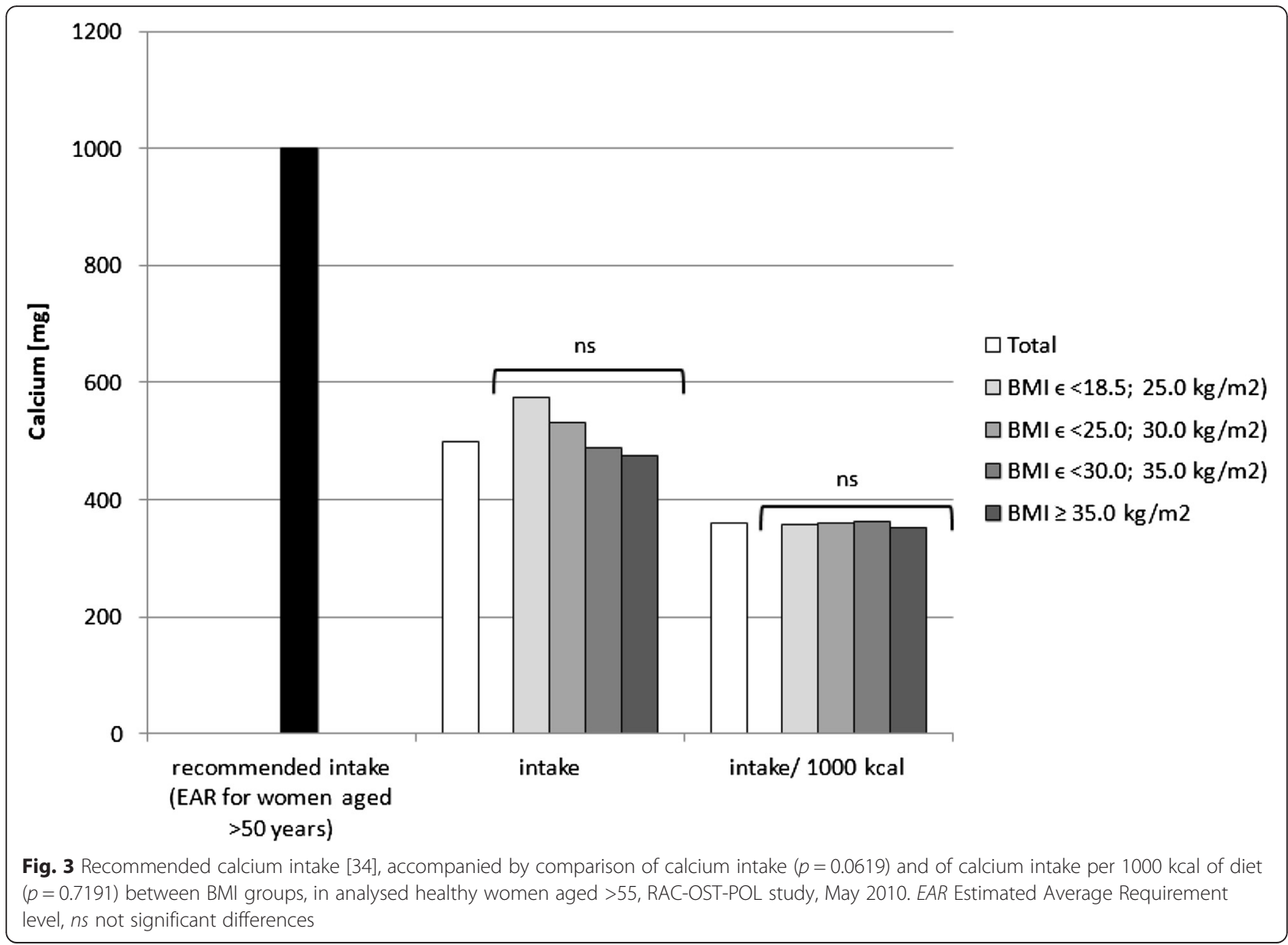

\section{Results}

Table 1 presents the characteristic features of the participants-their age, body weight, body height and BMI. The age subgroups accounted for the same proportions as in the general Polish population as was stated according to the Statistical Yearbook [30], the chi-square test revealed no significant differences between typical and observed numerical strength in the analysed group $(p=0.2078)$. Significant age differences were found between groups with normal body weight and obese individuals $(p=$ 0.0057 ) - the normal body weight subjects were younger.

The medians of energy value of the diet in groups with normal body weight, overweight, obese class I (BMI $\epsilon<$ $30.0 ; 35.0 \mathrm{~kg} / \mathrm{m}^{2}$ ) and obese class II/III individuals (BMI $\geq$ $\left.35.0 \mathrm{~kg} / \mathrm{m}^{2}\right)$ were, respectively, $1593 \mathrm{kcal}(807-2456 \mathrm{kcal})$, $1483 \mathrm{kcal}(773-2868 \mathrm{kcal}), 1421 \mathrm{kcal}(359-2652 \mathrm{kcal})$ and $1343 \mathrm{kcal}(646-3065 \mathrm{kcal})$ (the distribution of this factor in the groups was different than that in the normal) $(p=0.0271$ for the general difference between the BMI groups). It was concluded that the energy value of the diet differed in groups with normal body weight and obese class II/III individuals (difference of $250 \mathrm{kcal}$ for the comparison of medians; $p=0.0278$ ).
Sodium, potassium, calcium, phosphorus, magnesium, iron, zinc and copper intake in the diets as well as intake per $1000 \mathrm{kcal}$ in the analysed group of women, accompanied by the comparison between the BMI groups, is presented in Figs. 1, 2, 3, 4, 5, 6, 7 and 8, respectively.

No significant differences were observed in the analysed mineral intake in the diets between the BMI groups. Statistically significant differences of intake per $1000 \mathrm{kcal}$ between groups were observed for sodium $(p$ $=0.0081)$, potassium $(p=0.0169)$ and magnesium $(p=$ 0.0323 ). Individuals with normal body weight were characterised by lower sodium intake per $1000 \mathrm{kcal}$ of diet (about $100 \mathrm{mg} / 1000 \mathrm{kcal}$ ) in comparison with obese class II and III individuals (BMI $\geq 35.0 \mathrm{~kg} / \mathrm{m}^{2}$ ). Simultaneously, overweight individuals were characterised by lower potassium (about $250 \mathrm{mg} / 1000 \mathrm{kcal}$ ) and magnesium intake per $1000 \mathrm{kcal}$ of diet (about $20 \mathrm{mg}$ / $1000 \mathrm{kcal}$ ) in comparison with obese class I individuals $\left(\mathrm{BMI} \epsilon<30.0 ; 35.0 \mathrm{~kg} / \mathrm{m}^{2}\right)$.

The mineral content in the diets in the analysed group of women, in comparison with Polish recommendations for intake of analysed minerals (also presented in the Figs. 1, 2, 3, 4, 5, 6, 7, 8), and accompanied by a 


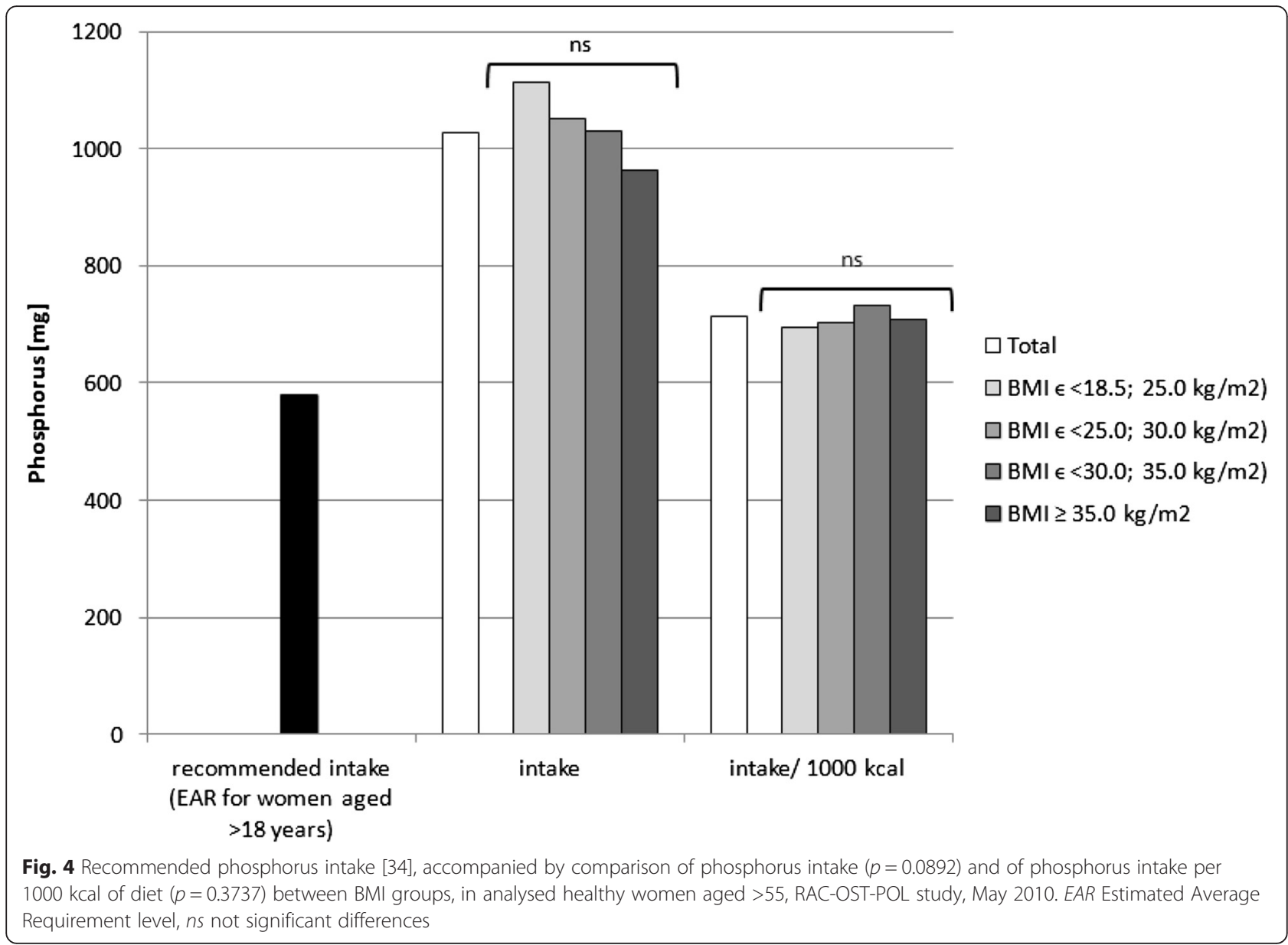

comparison of satisfying nutritional needs between the BMI groups, is presented in Table 2. Most of the individuals were characterised by insufficient intake of potassium, calcium and magnesium. No statistically significant differences in satisfying nutritional needs between the BMI groups $(p>0.05)$ were observed for all analysed minerals.

\section{Discussion}

In the research of Mirmiran et al. [31], the effect of under-reporting of energy intake on estimates of nutrient intake was determined. It was concluded that the under-reporters were characterised by a higher BMI in comparison with the normal-reporters, which was observed for both female and male subjects. Also, in a study by Goris et al. [32], it was stated that under-reporting by obese individuals is commonly observed and is explained by both under-recording and under-eating.

A similar conclusion may be reached in the analysed group when taking into account the significantly higher energy value of the declared diets of individuals with normal body weight than those from obese class II/III.
Under-reporting may be considered in the analysed group, as it is in general quite commonly stated in overweight and obese Caucasian female individuals [33] and older individuals [34] - it is more common than in male [33] and younger individuals [34]. The possible reasons for under-reporting among excessive body mass individuals have been stated to be associated with the fact that in Western countries, obesity is perceived as a highly stigmatised condition and obese individuals experience social pressure to reduce weight or even sometimes social discrimination [35].

Since the energy requirement is associated with, inter alia, physical activity and body mass [36], it may be concluded that in the group of female postmenopausal individuals, who were characterised by a similar physical activity level, in stable body mass conditions, individuals characterised by a higher BMI are simultaneously characterised by higher energy intake. Such under-reporting impacts the obtained nutritional value of the diets [37]. On the other hand, another reason for the observed situation may have been over-reporting of the physical activity level, which was observed in overweight female individuals [38]. 


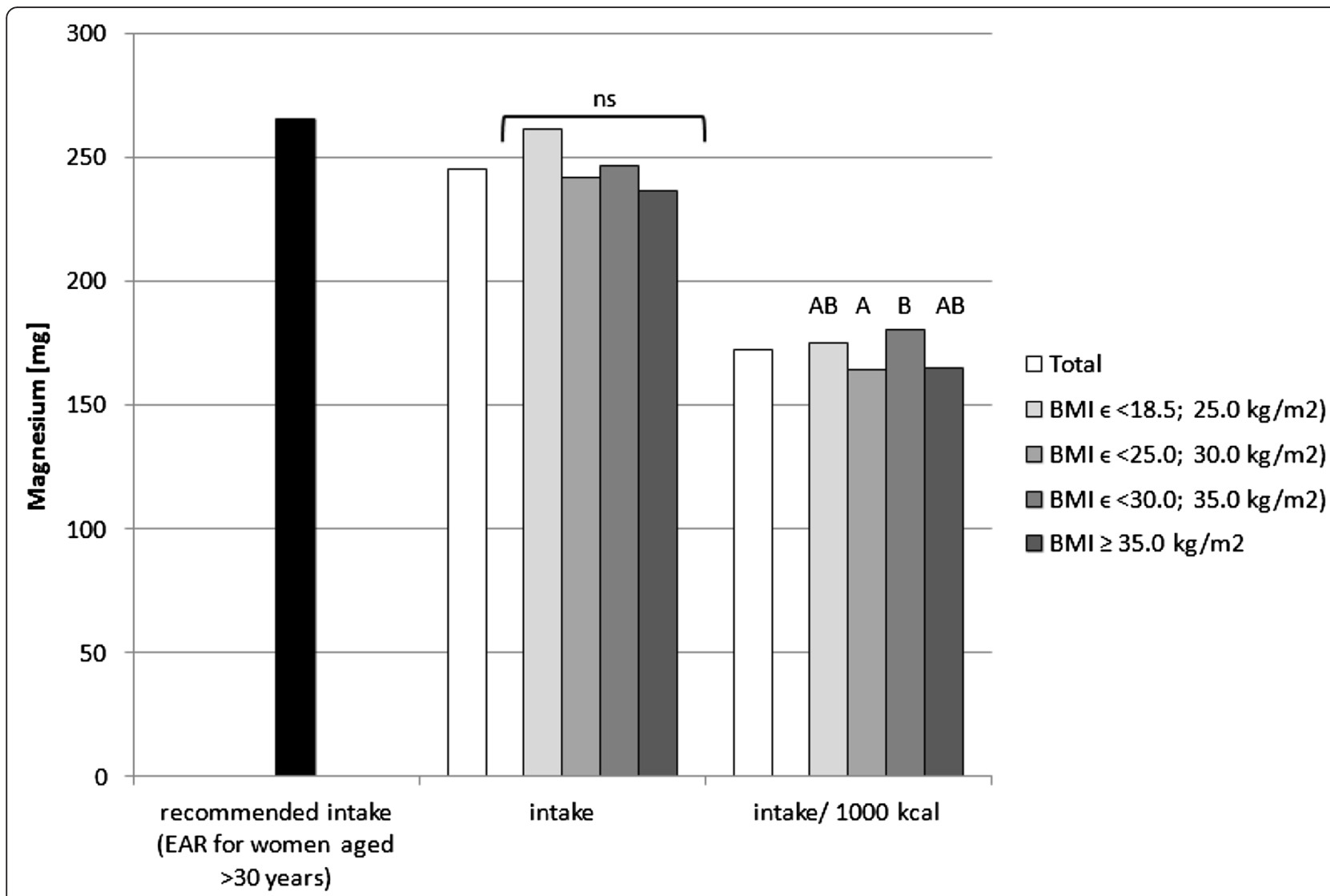

Fig. 5 Recommended magnesium intake [34], accompanied by comparison of magnesium intake ( $p=0.1497)$ and of magnesium intake per $1000 \mathrm{kcal}$ of diet $(p=0.0323)$ between BMI groups, in analysed healthy women aged $>55$, RAC-OST-POL study, May 2010. EAR Estimated Average Requirement level, ns not significant differences. $A$ and $B$ values with unlike letters were significantly different $(p<0.05)$

In the previously mentioned research of Mirmiran et al. [31], the intake of iron, calcium, phosphorus, magnesium and potassium was lower in the underreporters (who were simultaneously characterised by a higher BMI than that in the normal-reporters); however, following adjustment, no significant differences were observed. In the research presented, the observed under-reporting in the higher BMI individuals also impacted mineral intake; nonetheless, no differences were observed in the case of reported intake but were revealed after adjustment (recalculating the nutritional value per $1000 \mathrm{kcal}$ ). It may be concluded that if overweight and obese individuals report a reliable intake, differences in the case of the reported intake (without recalculation) would be observed, as the consumption of food products and, as a consequence, the intake of minerals in overweight and obese individuals is possibly higher than in normal body weight individuals.

Differences in nutrient density (between the nutritional value recalculated per $1000 \mathrm{kcal}$ ) were observed in the analysed group for sodium (normal body weight vs. obese class II and III individuals), potassium (overweight vs. obese class I individuals) and magnesium (overweight vs. obese class I individuals). For sodium and potassium, the same conclusions were formulated in a population-based Swiss research study, where the intake of sodium, potassium and protein increased across the BMI categories in both men and women with $p=0.001$ [39]. Similar observations were made in a Spanish FANPE study, where higher sodium intake was observed among excessive body weight than in normal body weight individuals [40]. Also, in the Olivetti Heart Study conducted in Italy, higher salt intake and altered renal sodium handling were observed in overweight and obese participants [41]. Equally, in the Italian MINISAL-SIIA study on hypertensive individuals, being overweight and obesity were associated with particularly high sodium intakes [42]. Despite the fact that in the research presented, sodium chloride addition during meal preparation was not taken into account, the presented results may be of great value as they result from natural sodium content in the products and sodium content in processed products chosen by the analysed subjects. 


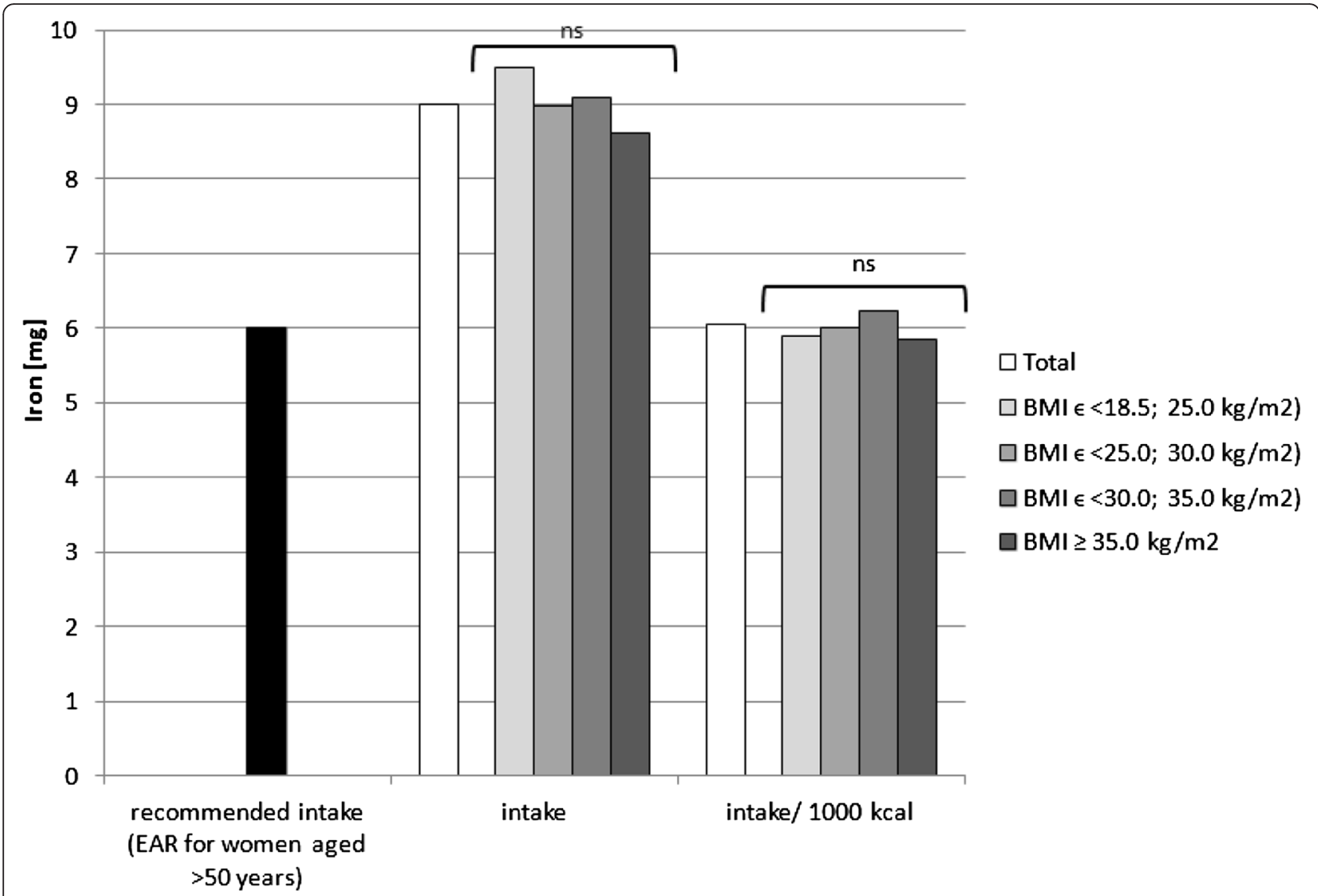

Fig. 6 Recommended iron intake [34], accompanied by comparison of iron intake ( $p=0.5120)$ and of iron intake per $1000 \mathrm{kcal}$ of diet $(p=0.1563)$ between BMI groups, in analysed healthy women aged >55, RAC-OST-POL study, May 2010. EAR Estimated Average Requirement level, ns not significant differences

The higher sodium intake that was observed in individuals characterised by higher BMI may result in higher blood pressure, as sodium intake is a well-known factor of hypertension development [43]. However, the results of Baudrand et al. [44] revealed that a high sodium diet is associated not only with hypertension but also with insulin resistance, dyslipidaemia and hypoadiponectinaemia, even when adjusting by confounding variables. Also, in the research of Aaron et al. [45], it was concluded that in obese adults, higher dietary sodium intakes were associated with albuminuria. As a consequence, high sodium intake is an additive mechanism in obesity-related metabolic disorders.

On the other hand, the higher potassium intake that was observed in the analysed group of obese individuals in comparison with overweight individuals is, according to the fourth Korean National Health and Nutrition Examination Survey (KNHANES IV), inversely associated with metabolic syndrome in adults [46]. This may result from the fact that a low serum potassium level is significantly associated with the prevalence of metabolic syndrome [47]. Taking into account the fact that potassium intake increases, similarly as sodium intake, across BMI categories, both in the research presented and in that of Ogna et al. [39], it may be the factor that reduces the potential frequency of obesity-related metabolic disorders in overweight and obese individuals.

Simultaneously, the higher magnesium intake that was observed in the analysed group for obese individuals in comparison with overweight individuals was also, according to the results obtained by other authors, associated with lower insulin resistance [48]. In the OLETF rat model (a model of diabetes type II with obesity), under conditions of excessive food intake, magnesium supplementation even delayed the development of diabetes [49]. Also, the meta-analysis of prospective cohort studies revealed that magnesium intake is significantly inversely associated with the risk of type 2 diabetes in a dose-response manner [50]. Similarly, as in the case of potassium, magnesium intake, which is higher in obese than in overweight individuals, may be the factor reducing the potential frequency of diabetes, which is one of the obesity-related metabolic disorders in overweight and obese individuals. 


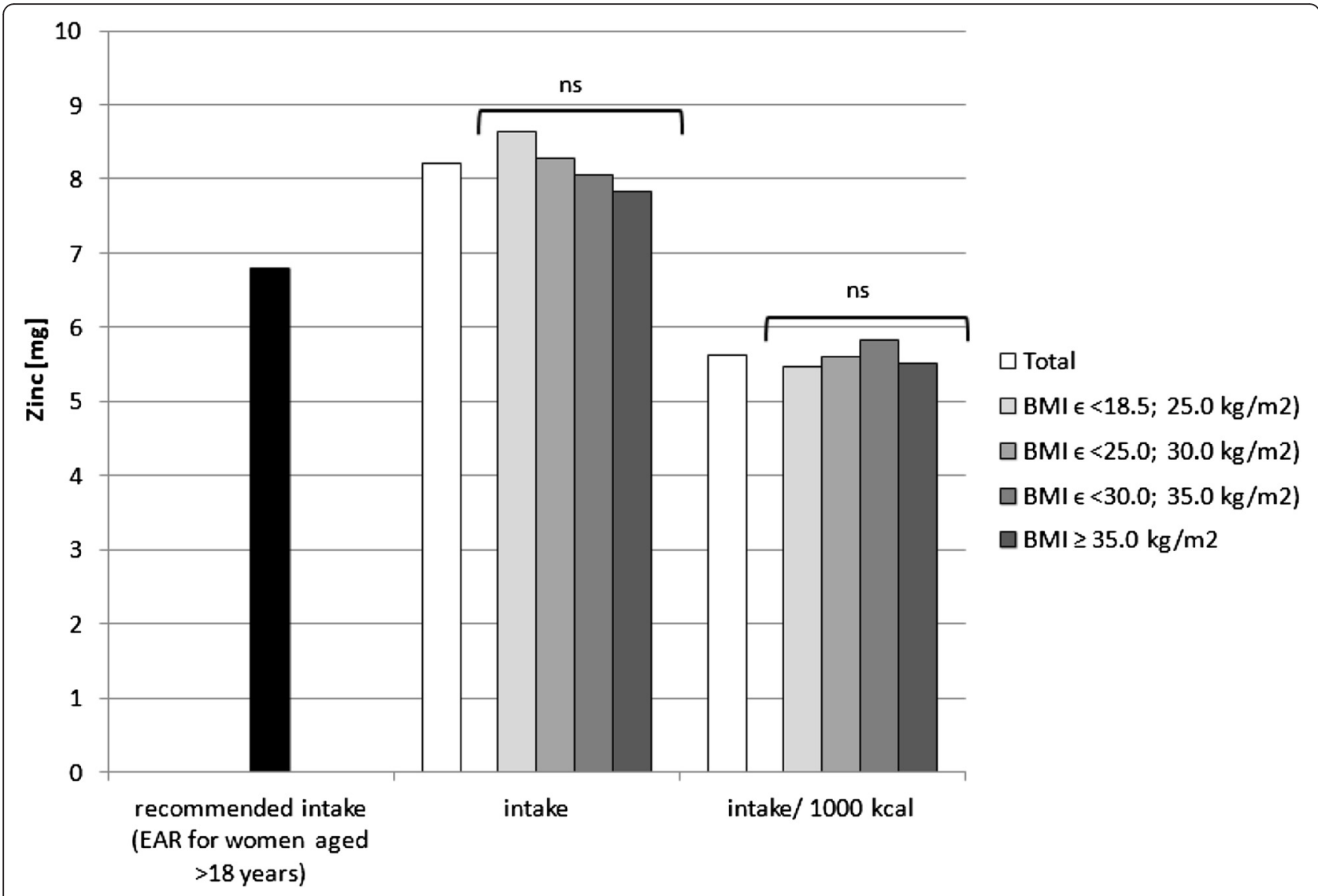

Fig. 7 Recommended zinc intake [34], accompanied by comparison of zinc intake ( $p=0.2771)$ and of zinc intake per $1000 \mathrm{kcal}$ of diet $(p=0.2324)$ between BMI groups, in analysed healthy women aged >55, RAC-OST-POL study, May 2010. EAR Estimated Average Requirement level, ns not significant differences

Potassium, calcium and magnesium are well-known factors associated, inter alia, with cardiovascular function [51], bone health [52] and neurological transmission [53]. Their deficiency may also be related to cancer development [54]. The diets of the analysed individuals cannot be defined as properly balanced, based on the low intake of potassium, calcium and magnesium-which were lower than the recommended level. Even if obese women have higher intake of potassium and magnesium than overweight women, in each group, over $90 \%$ of the subjects declared insufficient calcium and potassium intake, and over $50 \%$ declared insufficient magnesium intake. Moreover, it should be indicated that the absorption of the above-mentioned nutrients was not analysed, whereas it may also be influenced by vitamin intake, e.g. vitamin D intake may influence calcium [55] and magnesium absorption [56] or vitamins $\mathrm{A}$ and $\mathrm{B}$ may influence iron absorption [57].

Following an improperly balanced diet, especially if it is constant, may have serious medical consequences, as were mentioned previously (e.g. diabetes, hypertension, cardiovascular diseases); thus, nutritional education should be instituted in all BMI groups, as it is stated to be effective in improving the nutritional status and nutritional value of the diets of elderly patients [58]. Even if it is supposed that overweight and obese women under-reported consumption and the actual nutritional value of their diets was different (their mineral intakes were probably also higher), they need nutritional education to adjust the amount of consumed food products to their actual requirements and body mass.

In general, it may be stated that overweight and obese postmenopausal women probably under-report the amount of consumed food products, which influences the declared mineral intake. Sodium intake, which is higher for obese than for normal body weight female individuals, seems to be typical in population studies and may be an additional element contributing to metabolic syndrome development. Simultaneously, the higher nutrient density that was observed for potassium and magnesium in female postmenopausal individuals characterised by a higher BMI may partly counterbalance the negative impact of higher sodium intake. 


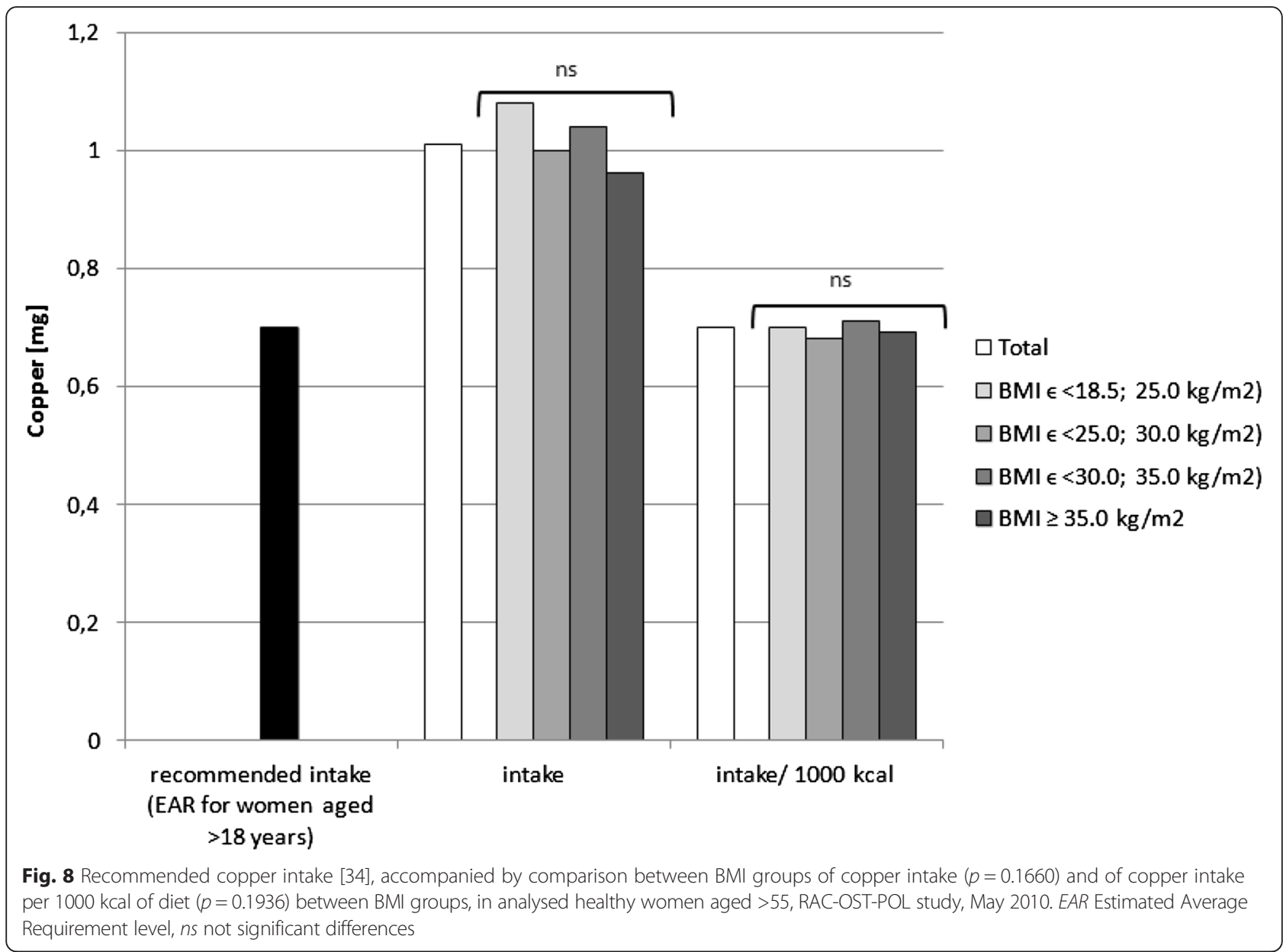

Table 2 Mineral content in diets in analysed group of healthy women aged >55, in comparison with recommendations, accompanied by comparison of satisfying nutritional needs between BMI groups, RAC-OST-POL study, May 2010

\begin{tabular}{|c|c|c|c|c|c|c|c|c|c|c|}
\hline Group & Number & $\%$ of group & $\mathrm{Na}$ & K & $\mathrm{Ca}$ & $P$ & $\mathrm{Mg}$ & $\mathrm{Fe}$ & $\mathrm{Zn}$ & $\mathrm{Cu}$ \\
\hline \multirow[t]{2}{*}{ Total } & 405 & Below Al/EAR & 39.3 & 96.3 & 92.1 & 4.7 & 61.2 & 6.2 & 28.1 & 10.6 \\
\hline & 405 & Above Al/EAR & 60.7 & 3.7 & 7.9 & 95.3 & 38.8 & 93.8 & 71.9 & 89.4 \\
\hline \multirow[t]{2}{*}{ BMl $\epsilon<18.5 ; 25.0 \mathrm{~kg} / \mathrm{m}^{2}$} & 61 & Below Al/EAR & 41.0 & 95.1 & 90.2 & 1.6 & 50.8 & 9.8 & 23.0 & 8.2 \\
\hline & 61 & Above Al/EAR & 59.0 & 4.9 & 9.8 & 98.4 & 49.2 & 90.2 & 77.0 & 91.8 \\
\hline \multirow[t]{2}{*}{ BMl $\epsilon<25.0 ; 30.0 \mathrm{~kg} / \mathrm{m}^{2}$} & 140 & Below Al/EAR & 42.1 & 99.3 & 92.9 & 7.1 & 65.7 & 3.6 & 26.4 & 8.6 \\
\hline & 140 & Above Al/EAR & 57.9 & 0.7 & 7.1 & 92.9 & 34.3 & 96.4 & 73.6 & 91.4 \\
\hline \multirow[t]{2}{*}{ BMle $<30.0 ; 35.0 \mathrm{~kg} / \mathrm{m}^{2}$} & 118 & below Al/EAR & 35.6 & 93.2 & 92.4 & 3.4 & 56.8 & 5.1 & 28.0 & 11.0 \\
\hline & 118 & Above Al/EAR & 64.4 & 6.8 & 7.6 & 96.6 & 43.2 & 94.9 & 72.0 & 89.0 \\
\hline \multirow[t]{2}{*}{$\mathrm{BMI} \geq 35.0 \mathrm{~kg} / \mathrm{m}^{2}$} & 86 & Below Al/EAR & 38.4 & 96.5 & 91.9 & 4.7 & 67.4 & 9.3 & 34.9 & 15.1 \\
\hline & 86 & Above Al/EAR & 61.6 & 3.5 & 8.1 & 95.3 & 32.6 & 90.7 & 65.1 & 84.9 \\
\hline$p^{a}$ & $p^{\mathrm{a}}$ & $p^{\mathrm{a}}$ & 0.7392 & 0.0751 & 0.9311 & 0.3080 & 0.0956 & 0.1915 & 0.3993 & 0.4156 \\
\hline
\end{tabular}

Na sodium, $K$ potassium, Ca calcium, $P$ phosphorus, $M g$ magnesium, Fe iron, $Z n$ zinc, Cu copper, Al Adequate Intake level (established for sodium and potassium), EAR Estimated Average Requirement level (established for calcium, phosphorus, magnesium, iron, zinc and copper)

${ }^{a}$ Differences assessed by the chi-square test 


\section{Conclusions}

In the analysed group of postmenopausal female individuals, it was observed that they were following an improperly balanced diet. It was stated that daily intake of all assessed minerals was not BMI-dependent for postmenopausal female individuals, but the nutrient density of the diet (for sodium, potassium and magnesium) was associated with BMI. It may be concluded that in the analysed group of postmenopausal female individuals, following an improperly balanced diet may contribute to a variety of negative health consequences and should be overcome by nutritional education.

\section{Acknowledgements}

Nothing to declare

\section{Authors' contributions}

DW and WP designed the RAC-OST-POL study project; DG, DW, AK, AC, BD and WP conducted the research; DG, DW and AK analysed the data and performed the statistical analysis; DG and DW wrote the paper; and DG designed the study and had the primary responsibility for the final content. All authors read and approved the final manuscript.

\section{Competing interests}

The authors declare that they have no competing interests.

\section{Ethics approval and consent to participate}

This study was conducted according to the guidelines laid down in the Declaration of Helsinki, and all procedures involving human subjects were approved by the Ethics Committee of the Medical University of Silesia, Katowice, Poland. A written informed consent was obtained from all participants.

\section{Author details \\ 'Department of Dietetics, Faculty of Human Nutrition and Consumer Sciences, Warsaw University of Life Sciences-SGGW, 159c Nowoursynowska Street, 02-776 Warsaw, Poland. ²Department of Nephrology, Regional Hospital in Racibórz, Racibórz, Poland. ${ }^{3}$ Department of Pathomorphology, Medical University of Silesia, Katowice, Poland. ${ }^{4}$ Metabolic Bone Diseases Unit, Department and Clinic of Internal Diseases, Diabetology and Nephrology, Medical University of Silesia, Katowice, Poland.}

Received: 18 July 2015 Accepted: 25 July 2016

Published online: 02 August 2016

\section{References}

1. Sharkey JR, Branch LG, Zohoori N, Giuliani C, Busby-Whitehead J, Haines PS. Inadequate nutrient intakes among homebound elderly and their correlation with individual characteristics and health-related factors. Am J Clin Nutr. 2002:76:1435-45.

2. Tur JA, Colomer M, Moñino M, Bonnin T, Llompart I, Pons A. Dietary intake and nutritional risk among free-living elderly people in Palma de Mallorca. J Nutr Health Aging. 2003;9:390-6.

3. Meng X, Kerr DA, Zhu K. Calcium intake in elderly Australian women is inadequate. Nutrients. 2010;2:1036-43.

4. Dumartheray EW, Krieg MA, Cornuz J, Whittamore DR, Lanham-New SA Burckhardt P. Energy and nutrient intake of Swiss women aged 75-87 years. J Hum Nutr Diet. 2006;19:431-5.

5. Paturi M Tapanainen $\mathrm{H}$, Reinivuo $\mathrm{H}$, Pietinen $\mathrm{P}$, editors. The National FINDIET 2007 Survey. Helsinki: National Public Health Institute B23/2008, 2008.

6. Ervin RB, Kennedy-Stephenson J. Mineral intakes of elderly adult supplement and non-supplement users in the third national health and nutrition examination survey. J Nutr. 2002;132:3422-7.

7. Martínez Tomé MJ, Rodríguez A, Jiménez AM, Mariscal M, Murcia MA, García-Diz L. Food habits and nutritional status of elderly people living in a Spanish Mediterranean city. Nutr Hosp. 2011;26:1175-82.
8. Volkert D, Kreuel K, Heseker $H$, Stehle P. Energy and nutrient intake of young-old, old-old and very-old elderly in Germany. Eur J Clin Nutr. 2004:58:1190-2100

9. Rolland Y, Pillard F, Garrigue E, Amouyal K, Riviere D, Vellas B. Nutritional intake and recreational physical activity in healthy elderly women living in the community. J Nutr Health Aging. 2005;9:397-402.

10. Wyka J, Biernat J, Mikołajczak J, Piotrowska E. Assessment of dietary intake and nutritional status (MNA) in Polish free-living elderly people from rural environments. Arch Gerontol Geriatr. 2012:54:44-9.

11. Wyka J, Biernat J. The comparison of food patterns of the elder people in 1990 and 2006. Rocz Panstw Zakl Hig. 2009;60:159-62 (in Polish).

12. Goluch-Koniuszy Z, Fabiańczyk E. Assessment of nutritional status and dietary habits persons of retired for up to six months. Rocz Panstw Zakl Hig. 2010;61:191-9 (in Polish)

13. Bailey RL, Mitchell DC, Miller C, Smiciklas-Wright H. Assessing the effect of underreporting energy intake on dietary patterns and weight status. J Am Diet Assoc. 2007;107:64-71

14. Cena H, Oggioni C, Turpini C, Negri F, Roggi C, Allegri C. Underreporting in obese inpatients undergoing a psycho-nutritional rehabilitative program. Eat Weight Disord. 2013;18:199-207.

15. Meng X, Kerr DA, Zhu K, Devine A, Solah VA, Wright J, et al. Under-reporting of energy intake in elderly Australian women is associated with a higher body mass index. J Nutr Health Aging. 2013;17:112-8.

16. Schoeller DA. Limitations in the assessment of dietary energy intake by selfreport. Metabolism. 1995;44 suppl 2:S18-22.

17. Johnson RK, Goran MI, Poehlman ET. Correlates of over- and underreporting of energy intake in healthy older men and women. Am J Clin Nutr. 1994:59:1286-90

18. Sallé A, Ryan M, Ritz P. Underreporting of food intake in obese diabetic and nondiabetic patients. Diabetes Care. 2006:29:2726-7.

19. Lührmann PM, Herbert BM, Neuhäuser-Berthold M. Underreporting of energy intake in an elderly German population. Nutrition. 2001:17:912-6.

20. Novotny JA, Rumpler WV, Riddick H, Hebert JR, Rhodes D, Judd JT, et al. Personality characteristics as predictors of underreporting of energy intake on 24-hour dietary recall interviews. J Am Diet Assoc. 2003;103:1146-51.

21. Scagliusi FB, Ferriolli E, Pfrimer K, Laureano C, Cunha CS, Gualano B, et al. Under-reporting of energy intake is more prevalent in a healthy dietary pattern cluster. Br J Nutr. 2008;100:1060-8.

22. Trabulsi J, Schoeller DA. Evaluation of dietary assessment instruments against doubly labeled water, a biomarker of habitual energy intake. Am J Physiol Endocrinol Metab. 2001;281:891-9.

23. Charzewska J, Chwojnowska Z, Wajszczyk B, Chabros W. The intake assessment at the individual and group level in comparison with recommendations. In: Jarosz $\mathrm{M}$, editor. Human nutrition recommendations for Polish population. Warsaw: IŻ̇ं: 2012. p. 172-81 (in Polish)

24. United Nations Organization. Provisional guidelines on standard international age classifications. United Nations publication ST/ESA/STAT/ SER.M/74, no. E.82.XVII.5. New York: United Nations Organization; 1982

25. Thompson FE, Larkin FA, Brown MB. Weekend-weekday differences in reported dietary intake: the nationwide food consumption survey, 1977-78. Nutr Res. 1986:6:647-62

26. Yang HW. A temporal analysis of Canadian dietary choices using the Canadian Community Health Survey Cycle 2.2: does nutrient intake and diet quality vary on weekends versus weekdays? Vancouver: The University of British Columbia; 2009 (M.Sc. Thesis).

27. Kunachowicz H, Nadolna J, Przygoda B, Iwanow K. Food composition tables. Warsaw: PZWL; 2005 (in Polish).

28. Jarosz M, editor. Human nutrition recommendations for Polish population. Warsaw: IZZŻ; 2012 (in Polish)

29. Włodarek D, Głąbska D, Kołota A, Adamczyk P, Czekajło A, Grzeszczak W, et al. Calcium intake and osteoporosis: the influence of calcium intake from dairy products on hip bone mineral density and fracture incidencepopulation-based study in women over 55 years of age. Public Health Nutr. 2014;17:383-9.

30. Central Statistical Office. 2010 Statistical yearbook. Warsaw: Central Statistical Office, 2010 (in Polish).

31. Mirmiran P, Esmaillzadeh A, Azizi F. Under-reporting of energy intake affects estimates of nutrient intakes. Asia Pac J Clin Nutr. 2006;15:459-64.

32. Goris AH, Westerterp-Plantenga MS, Westerterp KR. Undereating and underrecording of habitual food intake in obese men: selective underreporting of fat intake. Am J Clin Nutr. 2000;71:130-4. 
33. Johansson L, Solvoll K, Bjørneboe GE, Drevon CA. Under- and overreporting of energy intake related to weight status and lifestyle in a nationwide sample. Am J Clin Nutr. 1998;68:266-74.

34. Bedard D, Shatenstein B, Nadon S. Underreporting of energy intake from a self-administered food-frequency questionnaire completed by adults in Montreal. Public Health Nutr. 2004;7:675-81.

35. Macdiarmid J, Blundell J. Assessing dietary intake: who, what and why of under-reporting. Nutr Res Rev. 1998;11:231-53.

36. Food and Agriculture Organization of the United Nations. Human energy requirements. Report of a joint FAO/WHO/UNU expert consultation. Rome: FAO; 2001

37. Pomerleau J, Ostbye T, Bright-See E. Potential underreporting of energy intake in the Ontario Health Survey and its relationship with nutrient and food intakes. Eur J Epidemiol. 1999;15:553-7.

38. McMurray RG, Ward DS, Elder JP, Lytle LA, Strikmiller PK, Baggett CD, et al Do overweight girls overreport physical activity? Am J Health Behav. 2008;32:538-46.

39. Ogna A, ForniOgna V, Bochud M, Paccaud F, Gabutti L, Burnier M. Swiss survey on salt group: prevalence of obesity and overweight and associated nutritional factors in a population-based Swiss sample: an opportunity to analyze the impact of three different European cultural roots. Eur J Nutr. 2014;53:1281-90

40. Ortega ARM, López-Solaber AM, Pérez-Farinós N. Associated factors of obesity in Spanish representative sample. Nutr Hosp. 2013;28 suppl 5:56-62.

41. Venezia A, Barba G, Russo O, Capasso C, De Luca V, Farinaro E, et al. Dietary sodium intake in a sample of adult male population in southern Italy: results of the Olivetti Heart Study. Eur J Clin Nutr. 2010;64:518-24.

42. Galletti F, Agabiti-Rosei E, Bernini G, Boero R, Desideri G, Fallo F, et al. MINISAL-GIRCSI program study group: excess dietary sodium and inadequate potassium intake by hypertensive patients in Italy: results of the MINISAL-SIIA study program. J Hypertens. 2014;32:48-56.

43. Erdem Y, Arici M, Altun B, Turgan C, Sindel S, Erbay B, et al. The relationship between hypertension and salt intake in Turkish population: SALTURK study. Blood Press. 2010;19:313-8

44. Baudrand R, Campino C, Carvajal CA, Olivieri O, Guidi G, Faccini G, et al. High sodium intake is associated with increased glucocorticoid production, insulin resistance and metabolic syndrome. Clin Endocrinol (Oxf). 2014:80:677-84.

45. Aaron KJ, Campbell RC, Judd SE, Sanders PW, Muntner P. Association of dietary sodium and potassium intakes with albuminuria in normal-weight, overweight, and obese participants in the Reasons for Geographic and Racial Differences in Stroke (REGARDS) Study. Am J Clin Nutr. 2011;94:1071-8.

46. Shin D, Joh HK, Kim KH, Park SM. Benefits of potassium intake on metabolic syndrome: the fourth Korean National Health and Nutrition Examination Survey (KNHANES IV). Atherosclerosis. 2013;230:80-5.

47. Sun K, Su T, Li M, Xu B, Xu M, Lu J, et al. Serum potassium level is associated with metabolic syndrome: a population-based study. Clin Nutr. 2014;33:521-7

48. Cahill F, Shahidi M, Shea J, Wadden D, Gulliver W, Randell E, et al. High dietary magnesium intake is associated with low insulin resistance in the Newfoundland population. PLOS ONE. 2013;8(3):e58278. doi:10.1371/journal. pone.0058278

49. Nagai $N$, Ito $Y$. Effect of magnesium ion supplementation on obesity and diabetes mellitus in Otsuka Long-Evans Tokushima Fatty (OLETF) rats under excessive food intake. J Oleo Sci. 2013;62:403-8.

50. Dong JY, Xun P, He K, Qin LQ. Magnesium intake and risk of type 2 diabetes: meta-analysis of prospective cohort studies. Diabetes Care. 2011;34:2116-22.

51. Levitan EB, Shikany JM, Ahmed A, Snetselaar LG, Martin LW, Curb JD, et al. Calcium, magnesium and potassium intake and mortality in women with heart failure: the women's health initiative. $\mathrm{Br} J$ Nutr. 2013;110:179-85.

52. Tucker KL. Osteoporosis prevention and nutrition. Curr Osteoporos Rep. 2009; 7:111-7.

53. Espay AJ. Neurologic complications of electrolyte disturbances and acid-base balance. Handb Clin Neurol. 2014;119:365-82

54. World Cancer Research Fund/ American Institute for Cancer Research. Food, nutrition, physical activity, and the prevention of cancer: a global perspective. Washington DC: AICR; 2007.

55. Christakos S, Dhawan P, Porta A, Mady LJ, Seth T. Vitamin D and intestinal calcium absorption. Mol Cell Endocrinol. 2011;347:25-9.
56. Pointillart A, Denis I, Colin C. Effects of dietary vitamin D on magnesium absorption and bone mineral contents in pigs on normal magnesium intakes. Magnes Res. 1995;8:19-26.

57. Abbaspour N, Hurrell R, Kelishadi R. Review on iron and its importance for human health. J Res Med Sci. 2014;19:164-74

58. Kim BH, Kim MJ, Lee $Y$. The effect of a nutritional education program on the nutritional status of elderly patients in a long-term care hospital in Jeollanamdo province: health behavior, dietary behavior, nutrition risk level and nutrient intake. Nutr Res Pract. 2012:6:35-44.

\section{Submit your next manuscript to BioMed Central and we will help you at every step:}

- We accept pre-submission inquiries

- Our selector tool helps you to find the most relevant journal

- We provide round the clock customer support

- Convenient online submission

- Thorough peer review

- Inclusion in PubMed and all major indexing services

- Maximum visibility for your research

Submit your manuscript at www.biomedcentral.com/submit 